\title{
Comparison of the Erosional Performance of Alterative Slope Geometries
}

\author{
G.I. McPhail Metago Environmental Engineers (Australia) Pty Ltd, Australia \\ C. Rye Metago Environmental Engineers (Australia) Pty Ltd, Australia
}

\begin{abstract}
The principal criterion in specifying a dump or heap leach pad slope geometry is slope stability which requires that the overall slope of the facility be such that the facility remain stable under all reasonably conceivable conditions. However, long-term erosional performance is also an important criterion and one that frequently results in major construction costs to modify the slope geometry at closure. It is therefore prudent to consider erosional performance in the course of evaluating slope stability.
\end{abstract}

The required geometry for long-term erosional performance has long been a concern of regulators who have been under pressure from industry to provide guidelines that, if complied with, will ensure that the closed facilities automatically satisfy relinquishment requirements without a need for detailed justification.

To date, most guidelines have stipulated a slope geometry made up of a series of benches with slopes ranging from 18 degrees to natural angle of repose between the benches. However, observation of the performance of such benched slopes has shown poor performance generally related to silting up and overtopping of benches as well as severe gully erosion of the slope faces.

This paper documents the evaluation of a range of slope geometries using the erosion model SIBERIA. The paper provides a quantitative comparison of their relative erosional performance and presents criteria and guidelines for the selection of a dump or heap leach pad slope geometry to meet erosional performance requirements.

\section{Introduction}

Long-term erosional performance of a dump, stockpile or heap leach pad slope is as important as the overall stability of the slope since it is the one factor that most often stands between closure and relinquishment of long-term liability for the facility. Uncertainty with regard to the long-term performance of the closure measures makes regulators wary of granting relinquishment as, in so doing, the risks associated with this uncertainty pass on to the State.

Regulators have long been under pressure from industry to provide specifications for dump and heap leach pad slopes that, if complied with, will automatically ensure relinquishment. Understandably, given the uncertainties of long-term performance, the regulators have been reluctant to bow to this pressure and have gone only as far as issuing guidelines with a caveat that conformance with the guidelines will not guarantee relinquishment. Instead it is necessary for the mine operator to negotiate completion criteria which, if complied with over an agreed period of time, will remove all further obstacles to relinquishment.

However, adoption of the completion criteria approach does not avoid the need for the mine operator and the regulators to have a shared understanding of the long-term erosional performance of the slope. Specifically, there needs to be a shared appreciation of the fact that, left to its own devices, a slope will continue to erode indefinitely albeit at a progressively reducing rate as the slope flattens as a result of the erosion.

Vegetation is an effective method of reducing erosion provided the extent of vegetation cover is sufficient for the vegetation roots to bind the surficial materials effectively as well as slow down flow rates. Unfortunately, in the arid, semi-desert interior areas of Western Australia, vegetation cover that will significantly reduce erodability is unlikely to be naturally sustainable.

It is necessary to accept that erosion will continue. However, provided the erosion after relinquishment does not result in solids transport beyond the confines of the facility and does not result in gully formation to an 
extent that it will generate a safety risk, ie it poses minimal risk of failure to meet the duty of care requirements of preventing nuisance or negligence, there should be no reason not to be able to negotiate completion criteria based on an acceptable erosion rate and gully geometry.

To date, most guidelines have stipulated a slope geometry made up of a series of benches with slopes ranging from 18 degrees to natural angle of repose between the benches. However, performance of such benched slopes has been observed to be poor, usually due to silting up and overtopping of benches, followed by severe gully erosion of the slope faces.

The sections below describe a series of erosion simulations conducted on a $35 \mathrm{~m}$ high slope for a range of slope geometries. The simulations have been conducted using SIBERIA and have focused on quantification of:

- The volume of material eroded with time.

- The depth and spacing of gullies eroded into the surface.

- The influence of vegetative cover in reducing erosion.

The objectives of the simulations were to:

- Develop an understanding of the effectiveness of slope geometry in minimising erosion.

- Estimate the size of erosion containment bunds which will prevent the dispersion of solids and meet nuisance-related duty of care requirements.

- Estimate the nature of gully formation and from this obtain an understanding of negligence-related duty of care requirements.

\section{SIBERIA}

Siberia is a finite element-based erosion simulation model initially developed by Willgoose (Willgoose and Riley, 1998) almost 20 years ago. It was developed in 1989 as a long-term landform evolution modelling tool able to simulate the changing geometry of the eroding surface with time as materials are eroded and redeposited. Since then the model has gained credibility internationally and is recognised as the principal gully-modelling erosion simulation programme.

\subsection{Description of SIBERIA}

SIBERIA was developed to explore the linkages between the time evolving geomorphic form of natural landscapes and the hydrology and erosion processes occurring on them, and how these processes, in turn, determine the future evolution of the natural landform. SIBERIA works with a gridded digital terrain model which evolves in time in response to runoff and erosion derived from physically based erosion models.

The equations (Willgoose, 2005) applied in SIBERIA are based on commonly accepted erosion physics, specifically relationships between catchment area and runoff rate such as that typically used in regional flood frequency analysis:

$$
Q=\beta_{3} A^{m_{3}}
$$

$Q$ is the characteristic discharge out of the catchment, $\beta_{3}$ is the runoff rate, $A$ is the catchment area and $m_{3}$ is a coefficient. The characteristic discharge is the mean peak discharge.

The erosion model is similar to that used in traditional agricultural sediment transport models where the rate of sediment transport is related to discharge, slope and a transport threshold:

$$
Q_{s}=\beta_{1} Q^{m_{1}} S^{n_{1}} \text { - threshold }
$$

$Q_{s}$ is the mean annual sedimentation rate, $\beta_{1}$ is the erodability (including the material erodability, vegetation cover factor and any cropping practice factors (USLE terminology)), $S$ the slope, and $m_{1}$ and $n_{1}$ are parameters to be calibrated for the erosion process. The erosion is relatively insensitive to the exponent 
$n_{1}$ which is commonly taken as 2 . The exponent $m_{1}$ is modified during calibration to ensure that the concavity of the modelled slope is similar to the prototype. Commonly $m_{1}$ is in the range 1 to 1.5 . The threshold is a simple allowance for shear stress mobilisation of the material.

The threshold term applies to armoured slopes of clean (no fines) or bound materials which is not the case for the surface materials of most dumps, stockpiles or heap leach facilities and may therefore be discarded.

Equations (1) and (2) may be combined to yield equation 3 below:

$$
Q_{s}=\beta_{1} \beta_{3}^{m_{3}} A^{m_{1} m_{3}} S^{n_{1}}
$$

Solution of the above two equations by finite elements at each grid point is effected by SIBERIA to derive the eroded position of the grid point at the end of each time step. The eroded topography is therefore being continuously updated thus enabling the simulation of gully formation.

Over an extended period the parameters $\beta_{3}$ and $m_{3}$ remain essentially constant. It is therefore possible to write equation (3) as:

$$
Q_{s}=\beta_{1}^{\prime} A^{m_{1} m_{3}} S^{n_{1}}
$$

where

$$
\beta_{1}^{\prime}=\beta_{1} \beta_{3}^{{ }^{m_{3}}}
$$

Where calibrations are conducted using surveys of slopes over an extended period, and where the rainfall that occurred over that period can be regarded as representative of the long-term average and incorporates unseasonably high as well as low rainfall periods, it is possible to carry out the calibration to determine directly without the need to consider and specifically account for the rainfall-related parameters $\beta_{3}$ and $m_{3}$.

SIBERIA does not work with specific storm events or events of a particular recurrence interval. It has been found (Willgoose, 2006, pers. comm.) that long-term erosion is dominated by an accumulation of all rainfall events and provided the rain record is long enough to include high rainfall events it is not necessary to consider specific rainfall events.

\subsection{Erosion parameters adopted for this study}

Representative erosion parameters for un-vegetated slopes have been derived from calibrated erosion parameters from mine sites in Western Australia. For this study, parameters have been chosen to represent a highly erodible material in the upper range of those typically observed and may be characteristic of a topsoilbased cover. Parameters representative of a vegetated slope have, for the purposes of this assessment, been scaled from the un-vegetated slope parameters by reducing the parameter in accordance with observed reductions in erosion rates for vegetated slopes as documented in the literature (Cerda and Doerr, 2005; Collins, 2002; Morgan, 1995; Rice, 2003; Rosewell, 1997; and Toy and Foster, 1998). The adopted erosion parameters are summarised in Table 1.

Table 1 SIBERIA erosion parameters adopted for this study

\begin{tabular}{ccc}
\hline Parameter & No vegetation & $\begin{array}{c}\text { Vegetation cover to 30\% } \\
\text { of the exposed slope area }\end{array}$ \\
\hline$\beta_{1}{ }^{\prime}$ & 0.05 & 0.01 \\
$m_{1}$ & 1.36 & 1.36 \\
$n_{1}$ & 2 & 2 \\
\hline
\end{tabular}




\section{Slope geometries evaluated}

The following slope geometries have been evaluated for a typical dump, stockpile or heap leach pad height of $35 \mathrm{~m}$ :

- A single slope at natural angle of repose. This forms the base case and would be representative of a facility formed by end-tipping methods.

- A single slope at $16^{\circ}$. This has been selected as being marginally flatter than the normal $18^{\circ}$ set out in regulatory guidelines.

- A benched slope such that two benches $15 \mathrm{~m}$ wide are formed at equidistant heights of $11.5 \mathrm{~m}$ and $26^{\circ}$ to the horizontal within the $35 \mathrm{~m}$ slope.

- A benched slope as per 3 above but with nominal $2 \mathrm{~m}$ high crest bunds.

- A benched slope as per 3 above but with $4 \mathrm{~m}$ high crest bunds.

- A concave slope modelled on the shape of the 100 year eroded slope profile.

- A slope made up of two slopes such that the 100 year eroded slope profile is approximated.

The slopes are illustrated to scale in Figure 1.

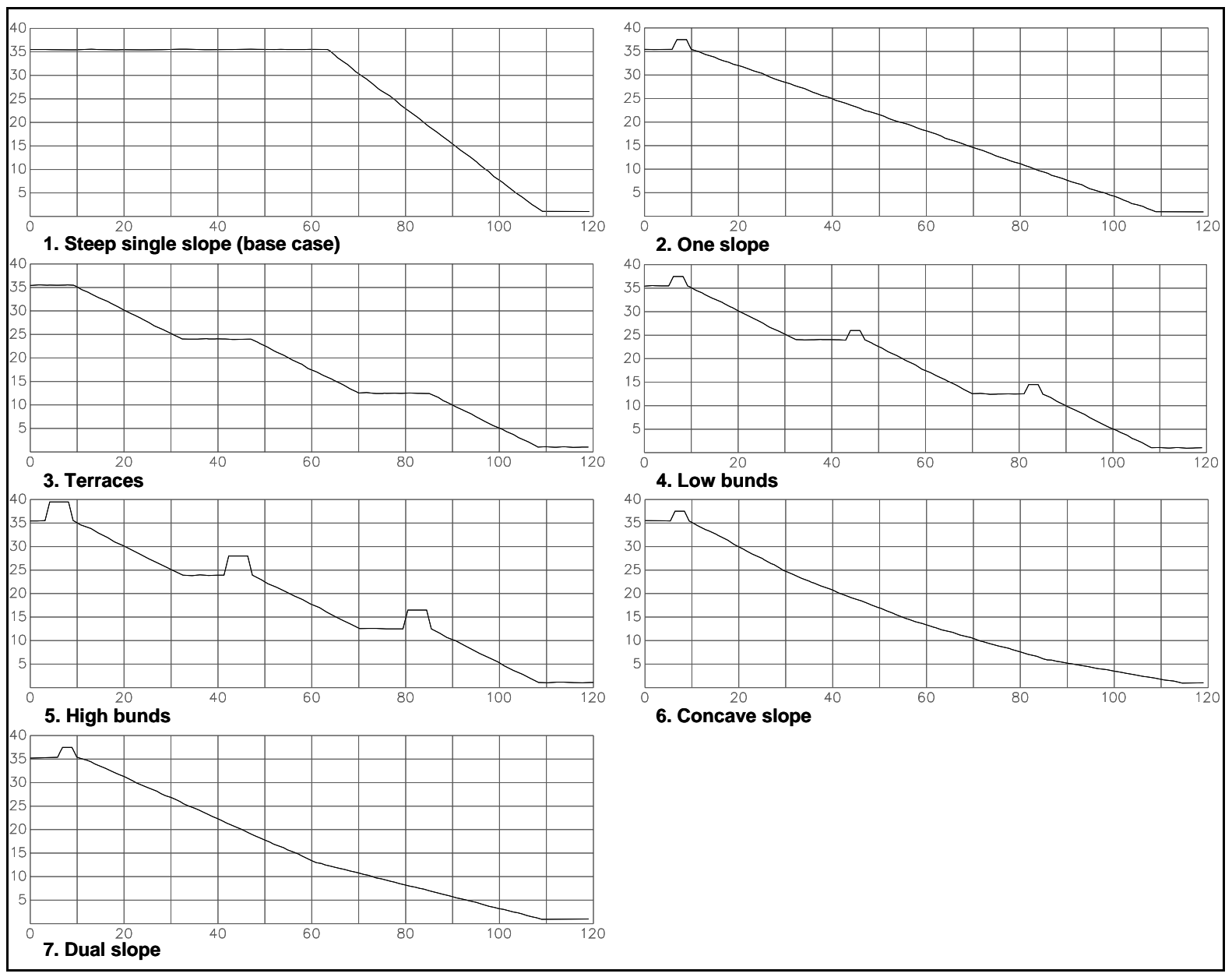

\section{Figure 1 Slopes simulated}

The width over which each slope has been simulated is $200 \mathrm{~m}$. 


\section{Incorporation of slope roughness}

In simulating the performance of engineered slopes it is important to incorporate the roughness and undulations that result from utilising large scale machinery to move materials often of large particle size. It is also important to simulate the effect of contour ripping which is the most common method of establishing vegetation on the slopes.

To achieve this on theoretical, computer generated slopes, undulations have been randomly generated on the slopes as follows:

- Along crest and toe lines to simulate construction tolerance - a maximum variation of $0.3 \mathrm{~m}$ in the horizontal and $0.1 \mathrm{~m}$ in the vertical per metre of crest or toe length has been incorporated.

- Between crests and toes to simulate contour ripping - maximum variation in contour ridges of $0.1 \mathrm{~m}$ per $\mathrm{m}$ vertically and $0.3 \mathrm{~m}$ per $\mathrm{m}$ horizontally have been incorporated.

One set of simulations have been conducted to indicate the difference between simulations that incorporate slope roughness and simulations that assume an idealistic smooth, regular surface.

\section{Results}

The results of the simulations are presented as follows.

\subsection{Graphical outputs}

Figure 2 through to Figure 9 show rendered isometric pictures of each slope and indicate the initial and the eroded slopes at 100 years. The figures also show cross sections and longitudinal sections through each slope as well as the eroded profiles at 50,100, and 200 years. While the actual widths of the slopes as modelled was $200 \mathrm{~m}$, only a section of the slope has been shown in the longitudinal sections.

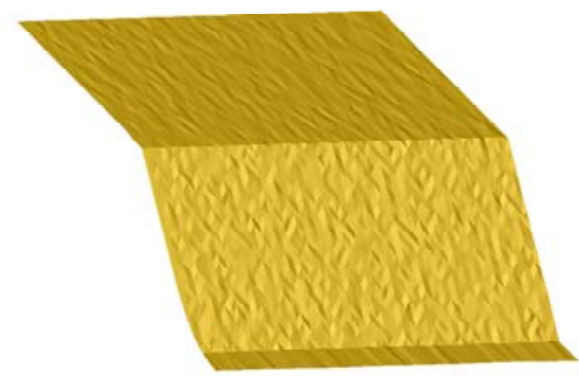

a) Before

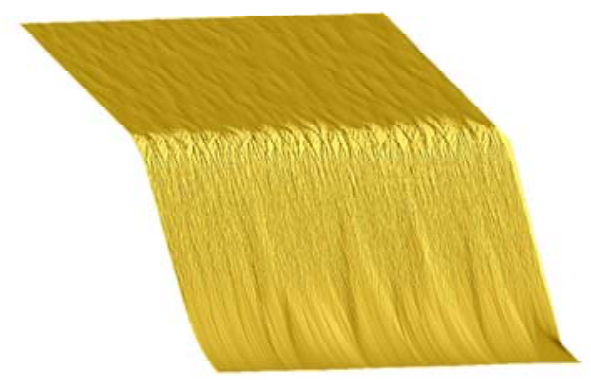

b) After 100 years

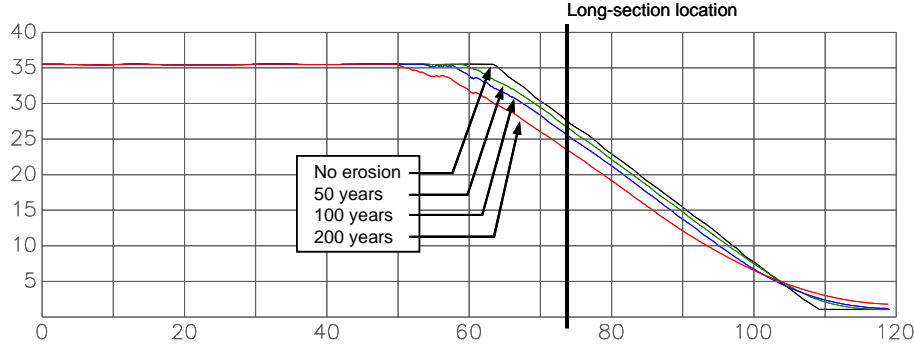

c) Cross section

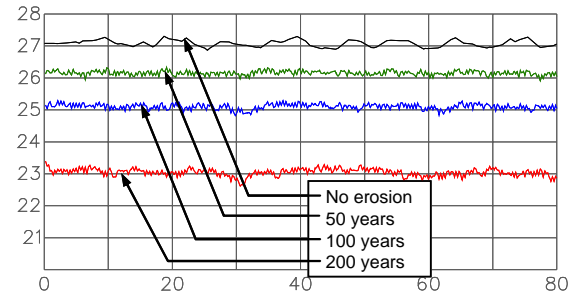

d) Longitudinal section

Figure 2 Single slope at natural angle of repose 


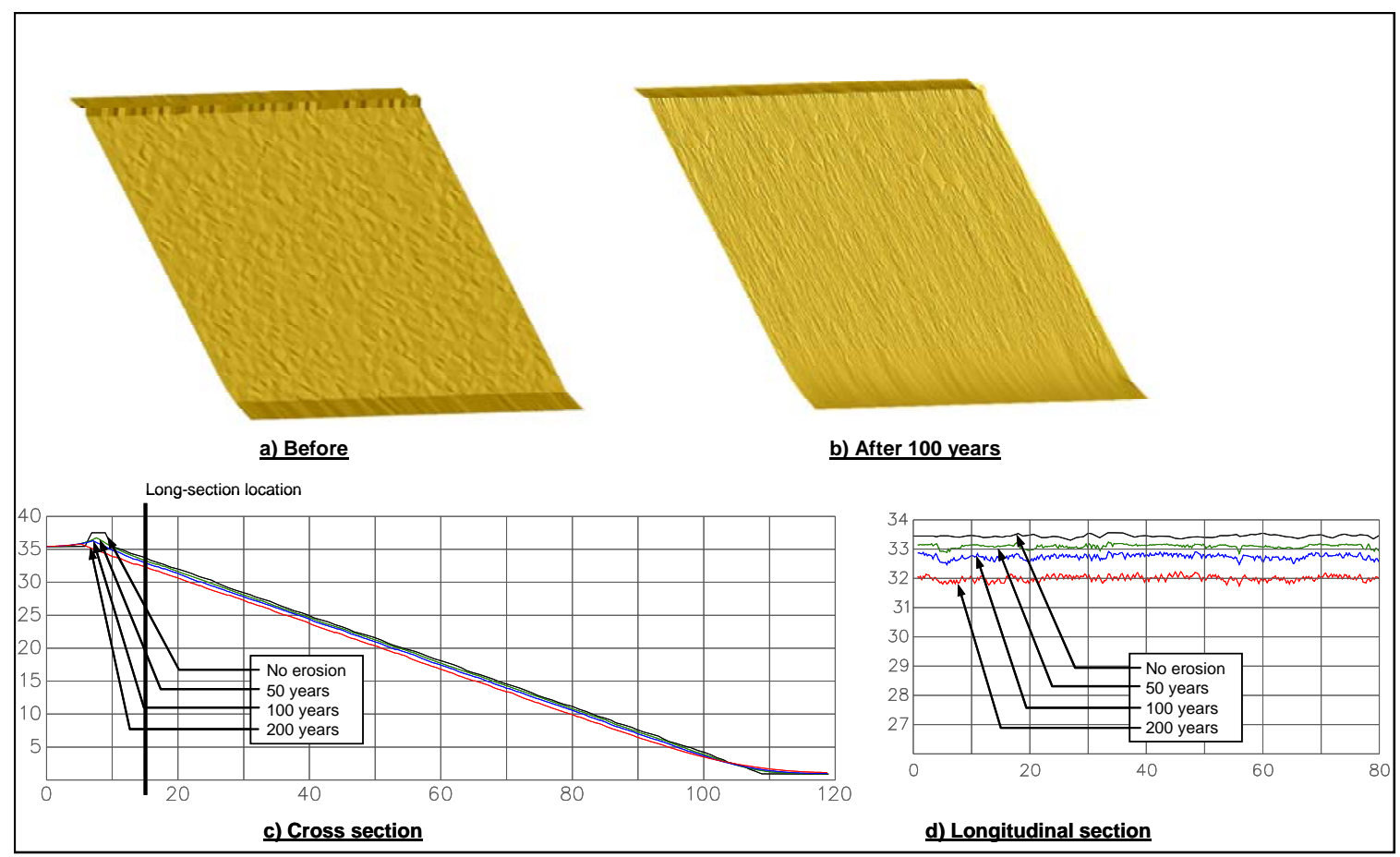

Figure 3 Single slope at $16^{\circ}$

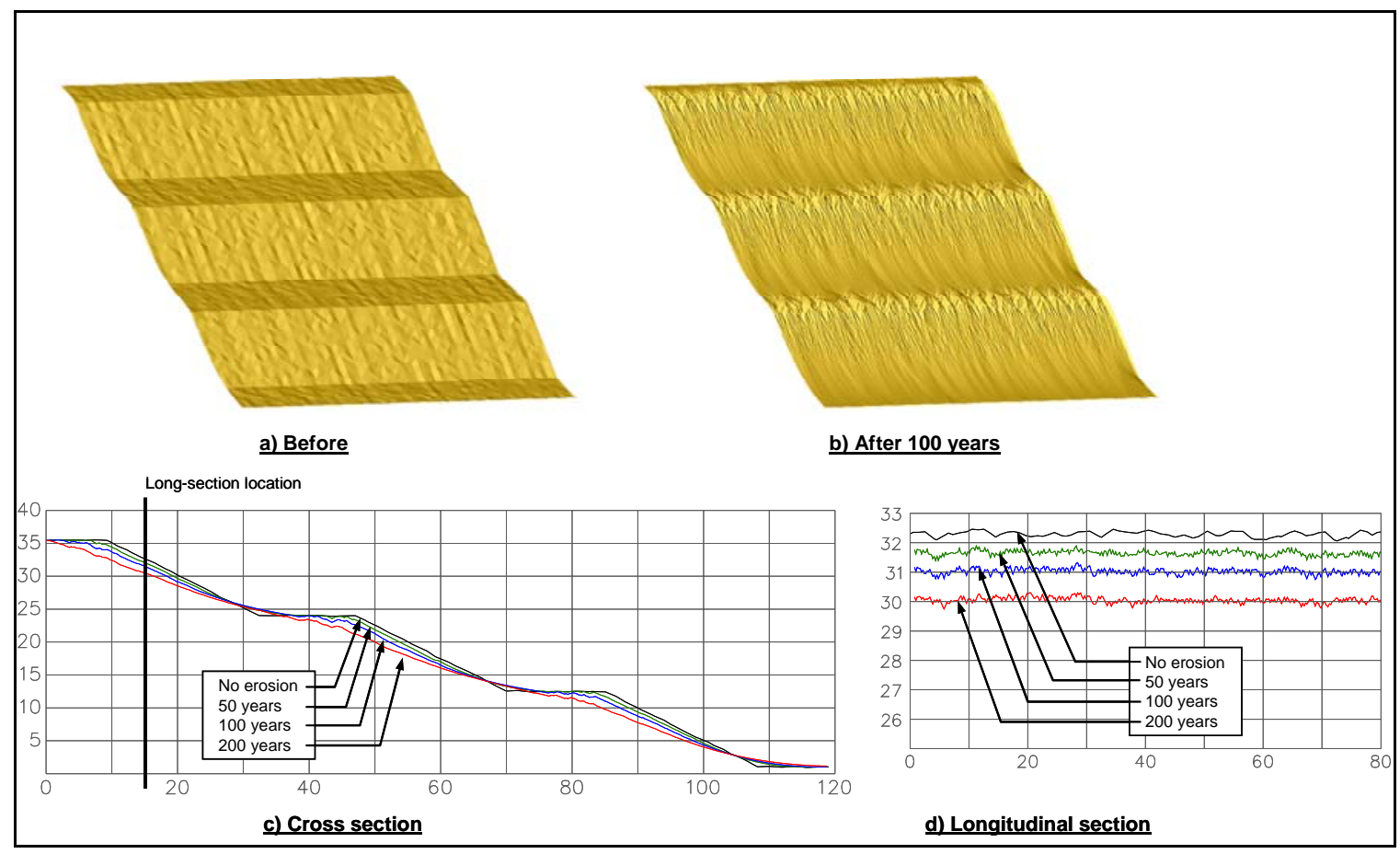

Figure 4 Benched slope no crest bunds 


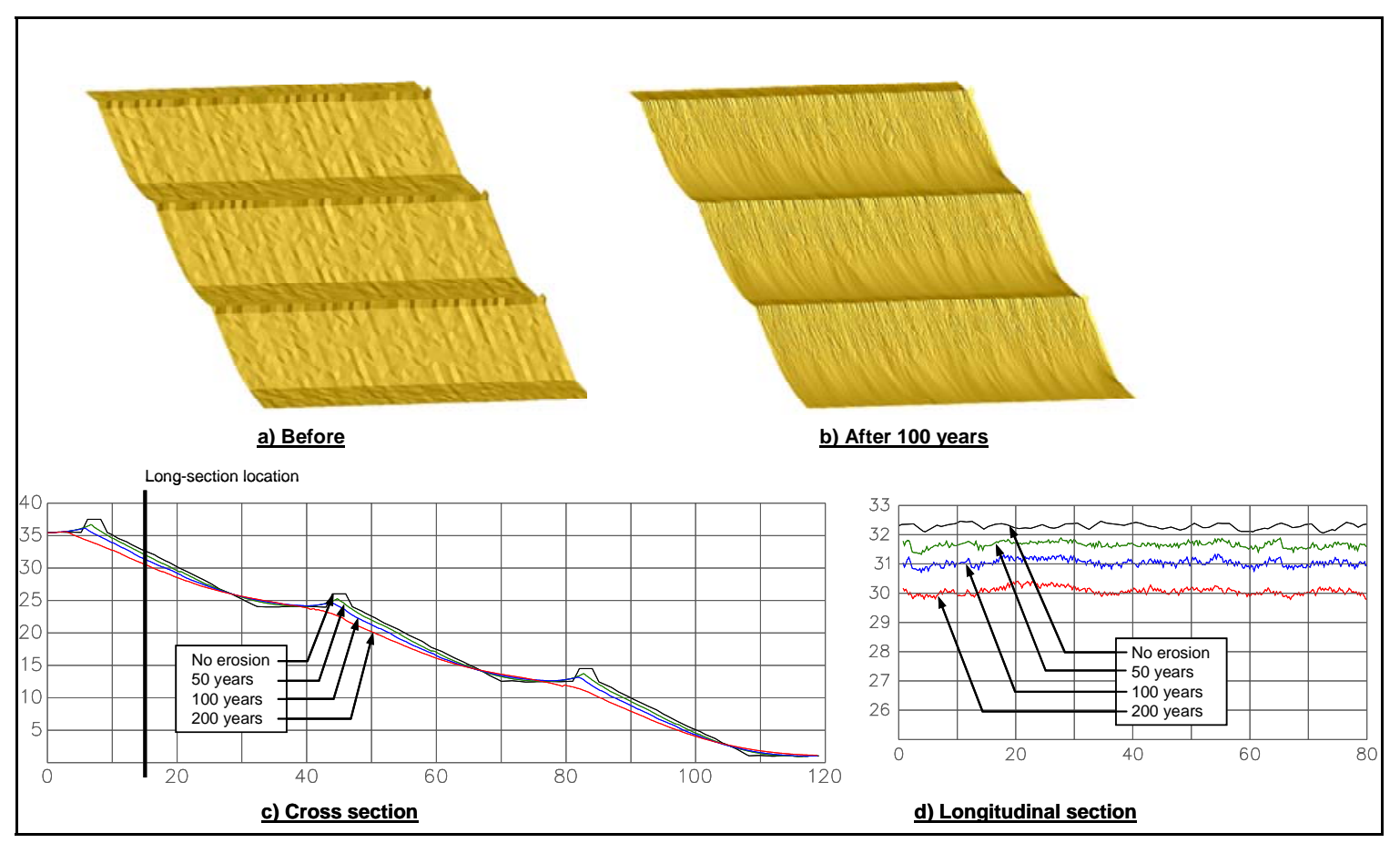

Figure 5 Benched slope nominal crest bunds that are overtopped

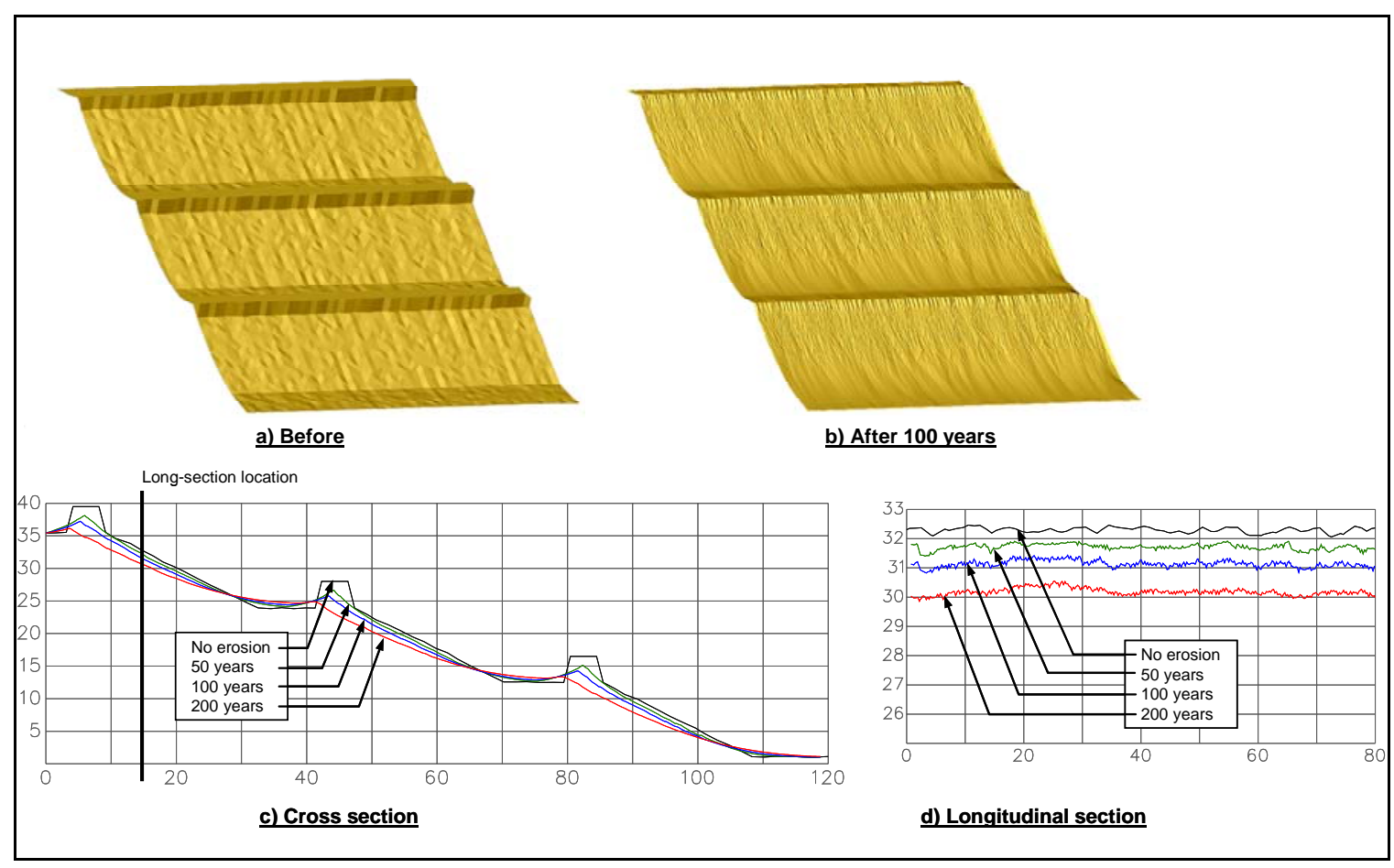

Figure 6 Benched slope with high crest bunds that are overtopped 


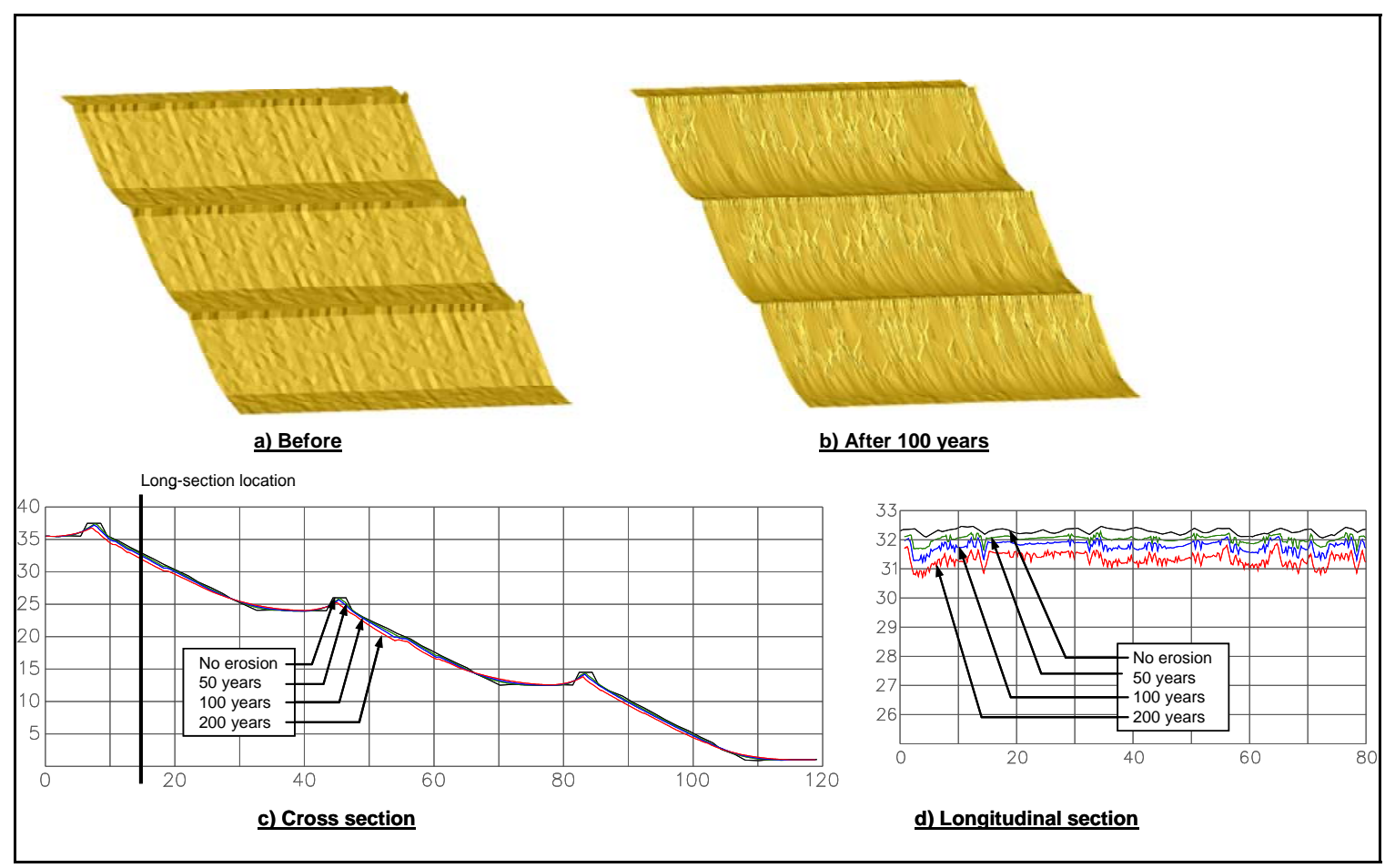

Figure 7 Vegetated benched slope with high crest bunds that are not overtopped

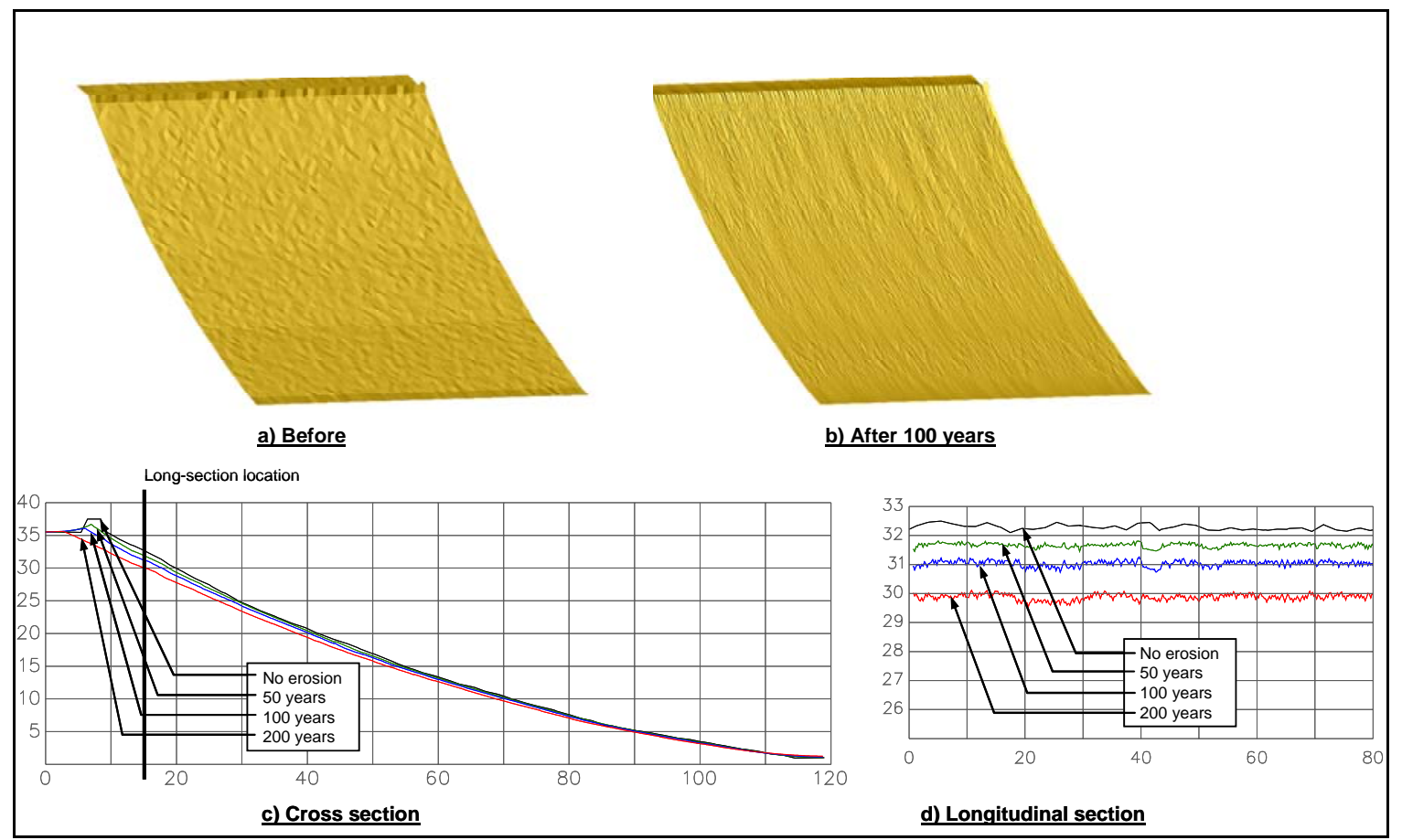

\section{Figure 8 Concave slope}




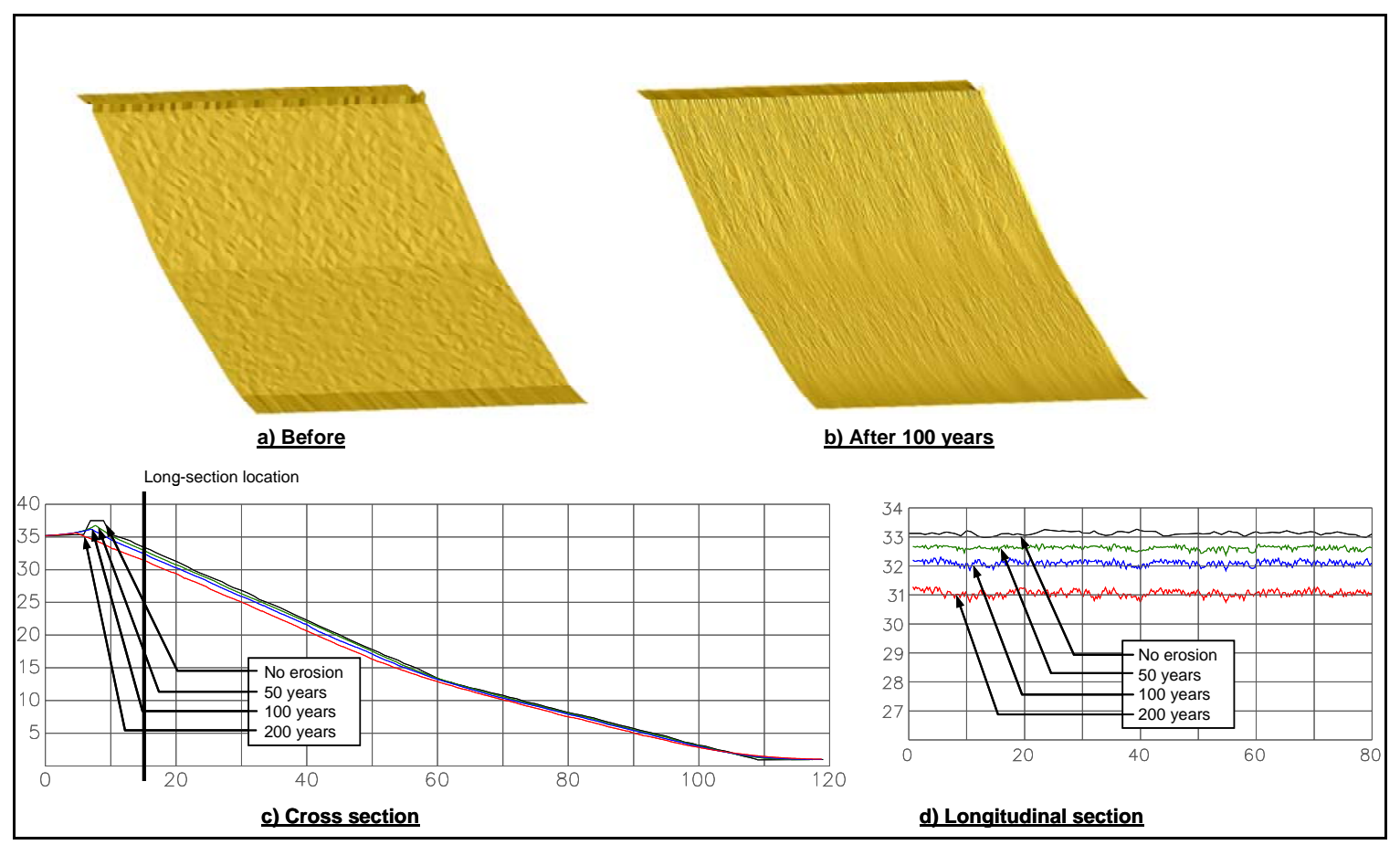

\section{Figure 9 Dual slope}

It is evident from these figures that:

- All slopes develop erosion gullies.

- Benched slopes erode severely where flow breaches the crest bunds as a result of siltation behind the bunds eliminating freeboard.

\subsection{Erosion rates and volumes}

Table 2 shows a summary of the cumulative eroded volume with time for the various sections. The steep single slope at natural angle of repose has been taken as the base case against which the relative erosion rates at 100 years have been rated yielding the percentage indicated in the last column of Table 2.

Table 2 Comparison of erosion rates (for a $200 \mathrm{~m}$ width of slope)

\begin{tabular}{|c|c|c|c|c|c|c|}
\hline \multirow[t]{2}{*}{ Section } & \multirow[b]{2}{*}{ Years: } & \multicolumn{5}{|c|}{ Eroded Volume $\left(\mathbf{m}^{3}\right)$} \\
\hline & & $\mathbf{0}$ & 50 & 100 & 200 & 100 \\
\hline High bunds overtop & & 0 & 7050 & 12096 & 20177 & $135 \%$ \\
\hline Low bunds overtop & & 0 & 4955 & 9287 & 16637 & $104 \%$ \\
\hline Steep single slope (base case) & & 0 & 3914 & 8965 & 18955 & $100 \%$ \\
\hline Terraces & & 0 & 4318 & 8733 & 16727 & $97 \%$ \\
\hline Dual slope & & 0 & 3453 & 7101 & 14234 & $79 \%$ \\
\hline One slope & & 0 & 3536 & 7096 & 13969 & $79 \%$ \\
\hline Concave slope & & 0 & 3298 & 6891 & 13817 & $77 \%$ \\
\hline High bunds no overtop + vegetation & & 0 & 1912 & 3480 & 6416 & $39 \%$ \\
\hline
\end{tabular}


Figure 10 shows a graphical representation of the cumulative erosion volume with time.

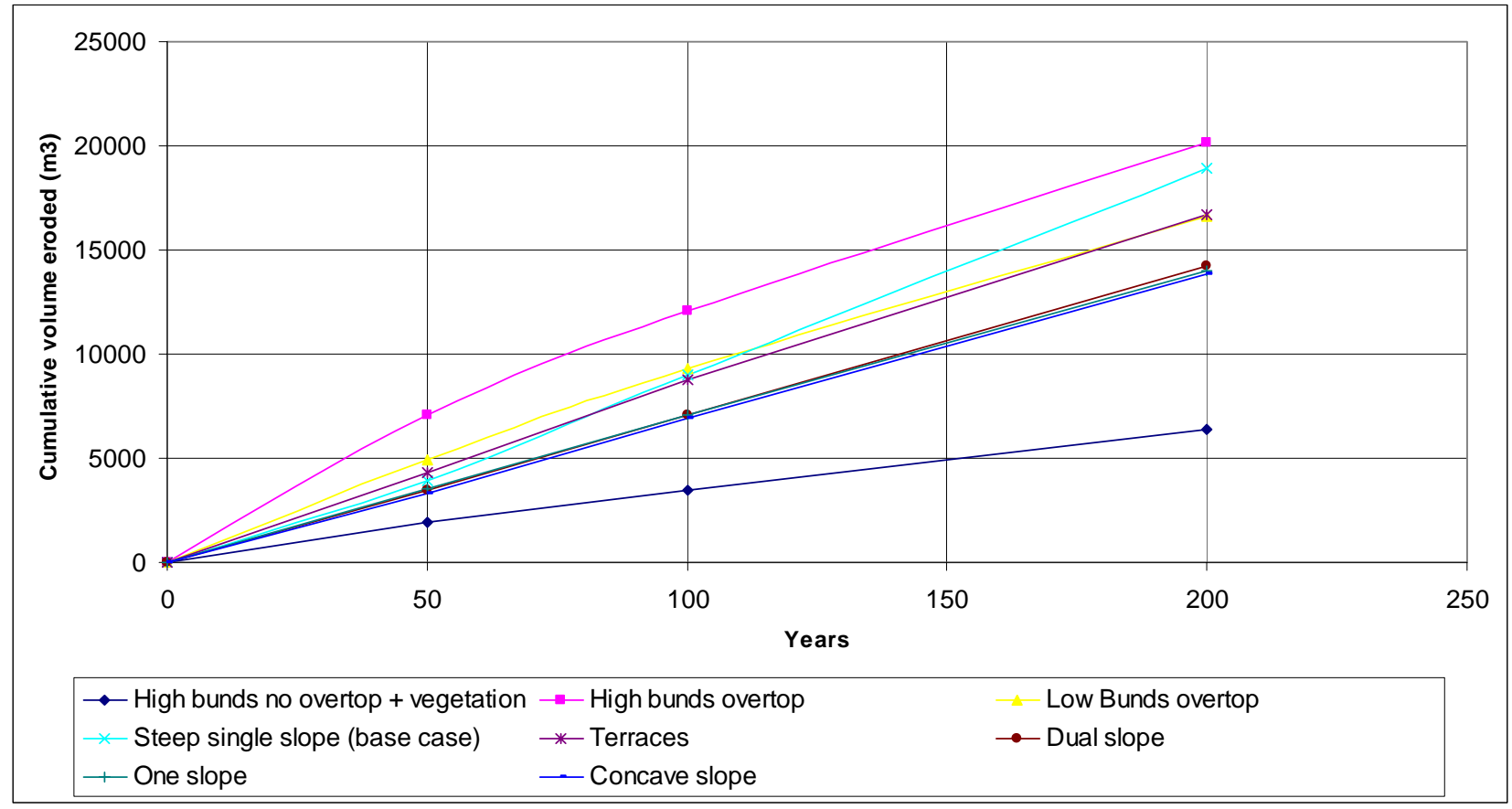

Figure 10 Cumulative erosion with time

It is may be deduced from the data in Table 2 and Figure 10 that:

- A benched slope where crest bunds are overtopped generates more erosion than a single slope at natural angle of repose. In fact, if large crest bunds are provided and these are overtopped the erosion is significantly more severe than for nominal crest bunds. This is because beyond 50 years the eroded slope profiles of the two slopes are similar indicating that the volume of the crest bunds adds to the volume of the eroded material. A larger bund that overtops merely adds a greater volume to be eroded.

- A benched slope where crest bunds are not overtopped shows only marginally less erosion than a single slope at natural angle of repose. While the slope length between benches is lower the erosion is not as sensitive to slope length as it is to slope angle.

- A concave slope modelled on the 100 year eroded slope profile produces the lowest erosion but this is still approximately $77 \%$ of the base case of a single slope at natural angle of repose.

- A single slope of $16^{\circ}$ and a dual slope that approximates the 100 year eroded profile produce similar eroded volumes. These are only marginally higher than the concave slope.

- At 100 years the volume of material eroded over a $200 \mathrm{~m}$ slope width is likely, for the parameters selected, to be of the order of $7000 \mathrm{~m}^{3}$ for the non-terraced profiles. In unit erosion terms this represents $84 \mathrm{t} / \mathrm{ha} /$ year assuming a density of $1.8 \mathrm{t} / \mathrm{m}^{3}$. This represents $35 \mathrm{~m}^{3}$ per metre. If a confining bund $1.5 \mathrm{~m}$ high were constructed around the toe of the structure, it would need to be some $25 \mathrm{~m}$ from the toe in order to contain the eroded material.

Table 3 shows a comparison of erosion rates for the same section with and without a vegetation cover of $30 \%$. 
Table 3 Comparison of erosion rates showing impact of vegetation

\begin{tabular}{lcccccc}
\hline Section & \multicolumn{5}{c}{ Eroded Volume $\left.\mathbf{( m}^{\mathbf{3}}\right)$} \\
\hline & Years & $\mathbf{0}$ & $\mathbf{5 0}$ & $\mathbf{1 0 0}$ & $\mathbf{2 0 0}$ & $\mathbf{1 0 0}$ \\
High bunds no overtop & & 0 & 3800 & 8705 & 18405 & $100 \%$ \\
High bunds no overtop + vegetation & & 0 & 1912 & 3480 & 6416 & $40 \%$ \\
\hline
\end{tabular}

It is evident that $30 \%$ vegetative cover would reduce erosion of the section analysed by some $60 \%$ compared with an un-vegetated section.

\subsection{Gully formation}

The longitudinal-sections on Figure 2 through to Figure 9 provide an indication of the extent of gully formation at 50,100 and 200 years. Table 4 shows a summary of gully statistics at 100 years.

Table 4 Summary of gully depths at 100 years

\begin{tabular}{lcc}
\hline Section & Max $(\mathbf{m})$ & Average $(\mathbf{m})$ \\
\hline High bunds overtop & 0.30 & 0.22 \\
Low bunds overtop & 0.25 & 0.21 \\
Steep single slope (base case) & 0.33 & 0.22 \\
Terraces & 0.35 & 0.22 \\
Dual slope & 0.28 & 0.23 \\
One slope & 0.25 & 0.21 \\
Concave slope & 0.40 & 0.24 \\
High bunds no overtop + vegetation & 0.43 & 0.24 \\
\hline
\end{tabular}

Gully depths have been taken as the maximum drop from a peak to an adjacent trough. In all of the cases modelled, the gully depths may be considered to present a low risk of negligence-related duty of care liability. It should be borne in mind, however, that the gully depths will vary from site to site depending on the nature of the eroding material and climatic conditions.

\subsection{Rough versus smooth surfaces}

A single simulation was carried out for a terraced slope with nominal bunds in which all crest lines were assumed to be idealistically straight and slopes idealistically smooth. The results indicate that the idealistic slope shows $31 \%$ less erosion after 100 years in comparison with the slope with a generated roughness. This difference is time-related since the idealistic surface lacks initial seed points from which erosion can initiate and it takes time for the erosive forces to begin to operate fully.

\section{Conclusions}

The analyses described above lead to the following conclusions:

- There is no merit in adopting guidelines that indicate a final abandoned slope profile made up of a series of benches. It would be better to terrace the slope and then doze the terraces out to form a contiguous slope. Indeed, a benched slope equipped with large crest bunds that are inadequately sized will result in significantly more erosion compared with a benched slope with nominal bunds. 
- There is significant merit in spacing and sizing benches such that on dozing at closure these would result in a concave profile. However, even then, erosion will only be reduced by approximately $30 \%$.

- On facilities where benches already exist, erosion will be significantly reduced if dozing to form either a single slope or a dual slope is carried out.

- For the parameters modelled, gully depths of up to $0.5 \mathrm{~m}$ could be anticipated. This would indicate low negligence-related duty of care risks over the long-term.

- Vegetation will assist in reducing overall erosion volumes and gullying. However, depending on the extent of cover it is possible that erosion gullying could develop as severely as on an un-vegetated slope in local areas where flow is able to pass unhindered between shrubs and trees.

- It is practical to construct confinement bunds around the toe of a dump or heap leach pad to contain erosion and reduce the nuisance-related duty of care risks. SIBERIA modelling enables the sizing and optimisation of the containment bund geometry.

It is important to note that in all of the sections analysed the top-most bench, i.e. the top surface of the dump or heap leach pad was assumed to be horizontal so that there would be no contribution of runoff from the top surface. Based on the observed poor performance of terraces that are overtopped it may be concluded that allowing any runoff from the top surface down the slope face, whether this is terraced or not, will significantly increase the erosion rate on the slope face. It is vital to prevent runoff from the top surface.

Finally, some comments in regard to the engineering design of slopes using erosion simulation models are warranted. Naturally, in terms of accuracy, simulation results are only as good as the calibrating parameters. However, even with approximate parameters, it is possible to optimise between alternatives in the manner indicated in this paper provided the parameters are representative of the actual situation, i.e. they take account of the specific material characteristics, site-specific climatic conditions and realistic levels of vegetation. For a reliable prediction of erosional performance over a given period of time it is vital to simulate irregularities on the crest lines and slope surface that, in the field, will result from earthwork tolerances and contour ripping to establish vegetation. These irregularities act as seed locations for the initiation and development of erosion and are therefore a key factor in erosion prediction.

\section{References}

Cerda, A. and Doerr, S.H. (2005) Influence of vegetation on soil hydrology and erodibility following fire: an 11-year investigation, International Journal of Wildland Fire, Vol. 14, No. 4, pp. 423-437.

Collins, S.M. (2002) Improving Rehabilitation Practices for the Outer Batter Slopes of Bauxite Residue Disposal Areas at Worsley Refinery, Collie, Western Australia, Murdoch University, Western Australia.

Morgan, R.P.C. (1995) Soil Erosion \& Conservation, Longman, London.

Rice, B. (2003) Hummock Grasslands in Australia, Macquarie University, New South Wales. Available from: $<$ http://www.bio.mq.edu.au/ecology/rice/spinifex.htm [24 August 2007].

Rosewell, C.J. (1997) Potential sources of sediments and nutrients: sheet and rill erosion and phosphorus sources, Australia: State of the Environment Technical Paper Series (Inland Waters), Department of the Environment, Sport and Territories, Canberra.

Toy, T.J. and Foster, G.R. (1998) Guidelines for the Use of the Revised Universal Soil Loss Equation (RUSLE) Version 1.06 on Mined Lands, Construction Sites, and Reclaimed Lands, The Office of Technology Transfer, Denver.

Willgoose, G.R. (2005) User Manual for Siberia, Telluric Research, New South Wales.

Willgoose, G.R. and Riley, S.J. (1998) Application of a catchment evolution model to the prediction of long-term erosion on the spoil heap at Ranger Uranium Mines: Initial analysis. Canberra, Australian Government Publishing Service. Supervising Scientist Report 132. 